\title{
UNA LECCIÓN SOBRE LA LECCIÓN SOCIOLÓGICA DE PIERRE BOURDIEU*
}

Fabián Sanabria S. *

"El mundo con sus jerarquías sociales que no se dejan relativizar tan fácilmente, no es relativista" (Pierre Bourdieu, Méditations pascaliennes, Paris, Seuil, 1997, p. 9).

Debería hablarse de un autor sin mayor inquisición en su trayectoria personal que la "confesión" consignada, a manera de "toma de posición", en sus obras. En lugar de preparar todo un arsenal de etiquetas tendíentes, en el mejor de los casos, a calificar "filiaciones académicas" resaltando los ismos terminales de "escuelas de pensamiento", sería mejor abordar directamente las frases centrales y aleatorias, determinadas por las condiciones sociales de producción de una obra, a fin de disponerse a realizar un ejercicio de "objetivación participante" que, sin ignorar los compases que lo condicionan, posibilitaría una relación más directa con un itinerario de investigación — de mayor alcance para quienes se disponen con paciencia crítica a aproximársele. De tal suerte, es para mí un honor presentar, por intermedio de estas líneas, mi aproximación académica al pensamiento del antropólogo y sociólogo francés Pierre Bourdieu; aproximación que espero sea para quienes la lean, una motivación más para encontrarse con esa obra. Y es quizás una proposición fundamental enunciar, ante todo, sea como parábola o paradigma, la "regla de oro" del discurso se que reflexiona a sí mismo en su propio acto de ser enunciado, en calidad de una de las propiedades más importantes del "programa socio político" concebido por el profesor Bourdieu: "todas las proposiciones que en este campo se enuncian pueden y deben aplicarse al sujeto que explicita dicha enunciación"10.

Porque, cuando en el análisis sociológico no se sabe introducir ese "efecto de distancia objetivante"; es decir, esa separación crítica que permite reconocer el abismo entre el decir y el hacer, entre las "cosas de la lógica" y la "lógica de las cosas", entre el opus operatum de la teoría y el modus operandi de la práctica; cuando no se tiene conciencia reflexiva respecto a la diferencia existente entre "construir cuadros de la realidad" y "vivir la realidad", se le concede "razón" a quienes ven en el científico social una suerte de "inquisidor", disponible a ejercer toda suerte de "policía simbólica". Por consiguiente, para volverse "socioanalista de lo político", es necesario desprenderse de todas las adherencias, mediante las cuales un agente social se aferra a un grupo, sin renegar de las creencias constitutivas de toda pertenencia o identidad, pero renunciando a todo lazo de

\footnotetext{
* Este ensayo está construido, a manera de paráfrasis o versión libre y comentada, con base en la lección inaugural de Pierre Bourdieu presentada el 23 de abril de 1982 en la cátedra de Sociología del Colegio de Francia. Pierre Bourdieu, Leçon sur la leçon. Leçon inaugurale prononcé au College de France le vendredi 23 avril, 1982, Edtions du Minuit, Paris, 1982.

** El autor es antropólogo y doctor en sociología de la Escuela de Altos Estudios en Ciencias Sociales de París; actualmente se desempeña como Profesor Asociado y Director de la Escuela de Ciencia Política en la Facultad de Ciencias Humanas y Económicas de la Universidad Nacional de Colombia, sede Medellín.

${ }^{9}$ Cf. Pierre Bourdieu, "Sur l'objectivation participante", en Actes de la Recherche en Sciences Sociales (ARSS), 23, Paris, EHESS, 1978.

${ }^{10} I d$., Réponses (avec Loic Wacquant), Paris, Seuil, 1992. 
afiliación o filiación. Así, el socio-analista ${ }^{11}$, consciente de sus propios condicionamientos sociales (procedente, en el mejor de los casos, de una "fracción dominada" de la "clase dominante") y llamado a conformar una cierta "elite", no puede acceder a la lucidez que alcanza toda especie de "desarraigo social", sino a condición de denunciar la representación populista del pueblo (que no engaña más que a sus creyentes), y la representación elitista de las elites (construida para engañar a la vez a quienes a ella pertenecen y a quienes no pueden alcanzarla).

Por ello, el análisis sociológico del poder encuentra armas para desmontar sus propias creencias, capaces de movilizar las adquisiciones de la ciencia contra esta misma; o sea, logra conquistas de su disciplina contra su propia formación, pues "sólo la historia nos libera de la historia"12. Es así como la historia social de la ciencia social, concebida como una "ciencia del inconsciente", en la gran tradición de epistemología histórica ilustrada por Georges Canguilhem y Michel Foucault, es uno de los medios más poderosos para liberarse de la historia o, mejor, del imperio de un pasado incorporado que sobrevive en el presente, o de un presente que —como el de las modas intelectuales- es ya pasado en el momento de su aparición ${ }^{13}$.

Y en esa tradición, la crítica epistemológica sólo es completa cuando está acompañada de una crítica social. Así, para romper con la ambición mitológica de "fundar en esencia las divisiones arbitrarias del orden social", y ante todo la división social del trabajo, pretendiendo una solución cosmológica al problema de la clasificación entre los hombres, el análisis sociológico debe tomar por objeto, en lugar de ignorar, la lucha por el monopolio de la representación legítima del mundo social y la lucha por las clasificaciones en tanto dimensiones de toda especie de lucha de clases: clases de edad, clases sexuales o clases sociales ${ }^{14}$. Porque las clasificaciones antropológicas se distinguen de las taxonomías botánicas o zoológicas en cuanto los objetos aquí clasificados -o desclasificados - pueden ser, a su turno, "sujetos reclasificables". O sea, que a pesar de la indignación del filósofo-rey, que pretende asignar esencias y funciones trascendentales a los seres que clasifica, los agentes clasificados, especialmente los mal clasificados, pueden sociológicamente rechazar los principios de clasificación que les asignan un lugar incierto en el mundo ${ }^{15}$.

En efecto, la historia lo ha demostrado, y ha sido casi siempre bajo la conducción de quienes pretenden alcanzar el monopolio del poder de clasificar frecuentemente ellos mismos mal clasificados, bajo ciertas condiciones en la clasificación dominante, que los dominados han podido liberarse de la clasificación imperante para transformar su propia visión, dejando a un lado sus límites incorporados; es decir, las categorías sociales de percepción del mundo.

De tal suerte, es una misma cosa descubrirse inevitablemente comprometido en la lucha por la construcción y la imposición de la taxonomía legítima, y el tomar por objeto la ciencia de esa lucha o el conocimiento y funcionamiento de las instituciones que en ese

\footnotetext{
${ }^{11}$ La noción de socioanálisis, en Bourdieu, es el resultado de un programa de investigación, de más de 30 años, construido como una "sociología de la percepción", que apunta no sólo a explicitar, tanto en individuos como en grupos, las "estructuras materiales" de la vida social o las "estructuras simbólicas" de ésta, sino la relación entre ambas (Cf. Ibid.).

${ }^{12}$ Id., "Le champ scientifique", en ARSS, 2-3, Paris, EHESS, 1976.

${ }^{13}$ Homo Academicus, Paris, Ed. de Minuit, 1984.

${ }^{14} I d$., Le sens pratique, Paris, Ed. de Minuit, 1980.

${ }^{15}$ No sólo existe una "sociología espontánea" que aparentemente "todo el mundo maneja"; es justo y necesario reclamar y defender el derecho a dotarse de instrumentos sociológicos para contestar la arbitrariedad del "orden establecido". Cf. Id., "Poscriptum" de $L a$ Distinction, Paris, Ed. de Minuit, 1979.
} 
"juego" perpetúan el orden establecido. Pensar como tal el espacio de la lucha por las clasificaciones -y la posición del analista en ese espacio o con respeto a él- no conduce la ciencia social a un relativismo. Sin duda, el analista de las relaciones sociales no es, siguiendo a Pierre Bourdieu, el "árbitro imparcial" o el "espectador omnipresente" — único ser apto a proclamar la "verdad"-, sino el agente social que se esfuerza por decir la veracidad de las luchas cuyo objeto es - entre otras cosas - la verdad. Por ejemplo, en lugar de transar entre quienes afirman y quienes niegan la existencia de una clase, de una nación o de un hecho social, el socioanalista trabaja con el ánimo de establecer la lógica específica de una lucha determinada, a través del análisis de las "correlaciones de fuerza" y de los "mecanismos de transformación", a fin de especificar las oportunidades posibles, probables o factibles de un hecho social dado.

El sociólogo debe entonces construir modelos capaces de dar cuenta de las luchas por la imposición de la representación verdadera de la realidad, que en tanto productos de toda la historia de las "luchas simbólicas", tienen por fin la existencia y definición de las clasificaciones, $y$ contribuyen a generar y a registrar realmente las clases ${ }^{16}$.

Pero basta pensar en el rol que las luchas políticas hacen jugar a la previsión para comprender que el analista de lo social, más rigurosamente aferrado a describir, "será siempre sospechoso de prescribir". En la existencia ordinaria no se habla casi nunca de lo que se es sino para decir, subrayando de paso, que aquello es conforme o contrario a la "naturaleza de las cosas": normal o anormal, admitido o excluido, bendito o maldito. Los nombres suelen extraerse de adjetivos tácitos, los verbos de adverbios silenciosos que tienden a consagrar o a condenar, a "instituir" como digno de existir y perseverar en su ser o, al contrario, a "destituir", degradar o desacreditar ${ }^{17}$. Así, la descripción científica de las relaciones, que los más desprovistos culturalmente tienen con la cultura científica, tiene todas las posibilidades de ser comprendida como una manera disimulada de "condenar al pueblo" o, a la inversa, como una forma jesuítica de "rehabilitar la incultura" y de devastar los "valores de la cultura" ${ }^{18}$ Y ¿qué no decir de los casos en los que el esfuerzo de "dar razón", en lo cual consiste generalmente el trabajo de la ciencia, pareciera una manera de "justificar", de "disculpar"?

Ante la servidumbre del trabajo subvalorado o la tragedia de los cinturones de miseria de nuestras ciudades, sin hablar de la guerra, el terrorismo, los desplazamientos forzados de grupos y familias enteras, la violencia o la tortura en los viejos y nuevos campos de concentración, el "así es la vida" pronunciado cual profeta iluminado ante las montañas, reviste el valor de una complicidad criminal. Por consiguiente, nada es menos neutro, cuando se trata de la vida social, que enunciar el ser con autoridad; es decir, con el poder de hacer ver y hacer creer que confiere la capacidad reconocida de prever, cuando las

\footnotetext{
${ }^{16}$ Es así como Bourdieu ha puesto en perspectiva su obra bajo el "signo de Pascal" pues, "si el mundo me comprende como un círculo comprende a un punto... yo con mi pensamiento puedo comprender al mundo". Cf. Meditations pascaliennes, Paris, Seuil, 1997.

${ }^{17}$ Id., "Décrire et prescríre. Notes sur les conditions de possibilité et les limites de l'efflcacité polítíque", en ARSS, 38, Paris, EHESS, 1981.

18 ، Hablamos de "forma jesuítica” siguiendo la definición dada por el Petit Larousse: "La misma expresión de la hipocresía”. 
constataciones de la ciencia ejercen inevitablemente una eficacia política que no necesariamente suele ser la deseada por el científico ${ }^{19}$.

De tal suerte, quienes deploran el pensamiento desencantador o los efectos desmovilizadores del análisis sociológico cuando éste formula, por ejemplo, las leyes de la "reproducción social", tienen argumentos tan fundados como aquellos que reprocharon a Galileo el haber desaconsejado el sueño de volar tras construir la ley de la "caída de los cuerpos". Enunciar una ley social, como aquella del profesor Bourdieu, que establece y demuestra cómo el capital cultural multiplica el capital cultural, es ofrecer la posibilidad de introducir entre las circunstancias propias que esa ley prevé —en el caso particular, la eliminación escolar de los agentes sociales más desprovistos de capital cultural — los "elementos modificadores", que, aunque siendo débiles, pueden contribuir a transformar, a partir del sentido de nuestras expectativas, el funcionamiento de los mecanismos ${ }^{20}$.

De hecho, al permitir el conocimiento de los mecanismos, determinar las condiciones y los medios de una acción destinada a manejarlos, el rechazo del sociologismo que trata lo probable como un "destino", es justificado; y los "movimientos de emancipación" están allí para probar que una cierta dosis de utopía -esa negación mágica de lo real que pareciera "neurótica"- puede aún contribuir a crear las condiciones políticas para una negación práctica de la constatación realista. Pero, sobre todo, el conocimiento de los "juegos sociales" ejerce en sí un "efecto liberador": la mayoría de los mecanismos ante los cuales el pensamiento sociopolítico establece las leyes de funcionamiento, se debe especialmente a un desconocimiento, más específicamente, a una negación del conocimiento de éstos, directamente relacionada con la "violencia simbólica" que garantiza el orden social, esa forma particular de violencia que no puede ejercerse sino sobre "sujetos que conocen, pero en los cuales los actos de conocimiento, en tanto parciales y mistificados, encierran el reconocimiento tácito de la dominación implicada en la negación de los verdaderos fundamentos de ésta. Así es como quienes ejercen el comercio simbólico dominante, necesitan del desconocimiento, y suelen ser los principales contestatarios del estatuto científico de la sociología ${ }^{21}$.

\section{III}

La necesidad de repudiar la "tentación regalista" se impone, entonces, cuando se trata de pensar el mundo científico mismo, y más ampliamente, el "campo intelectual". Si ha sido necesario volver a pensar completamente la "sociología de los intelectuales", es que el hecho mismo de tener intereses en ese "juego", de hacer inversiones y multiplicar acciones en ese campo, ha generado enormes dificultades en los intelectuales, para escapar a la lógica de la lucha en la cual cada quien se vuelve voluntariamente "sociólogo" - en I sentido más sociologista- de sus adversarios, al tiempo que todos se convierten en sus propios ideólogos, según las leyes de suficiencias cruzadas, que arreglan todas las luchas sociales por la "verdad". Ha sido, por lo tanto, a condición de aprehender el juego en tanto tal, con sus intereses y estrategias, sus reglas $y$

\footnotetext{
${ }^{19}$ Según Bourdieu, es necesario resistir metodológica y teóricamente a dos tentaciones: la tentación del “jamás visto” (“Se avecina una mutación, una gran revolución, es el Apocalipsis..."

-comentarios típicos de una conversación de "café de comercio"), y la tentación del "no hay nada nuevo bajo el sol" ("La vida es así, qué le vamos a hacer, buena suerte y mala suerte, siempre hay ricos y pobres, dominantes y dominados, burgueses y proletarios, los de arriba y los de abajo..."- comentarios típicamente conservadores, próximos a una conversación de "Café De flor"). Cf. Ce que parler veut dire, Paris, Fayard, 1982.

${ }^{20}$ No se trata de enunciar cínicamente, con argumentos sociológicos, el "principio Mateo", consistente en dar de sobra al que tiene y restarle al que no tiene hasta lo poco que posee. Se busca simplemente mostrar cómo se constituyen las "noblezas de Estado", porque como bien lo dice el refrán que desaconseja a quien "no pertenece al clan": "nobleza obliga". Cf. Id., La noblesse d'Etat, Paris, Ed. de Minuit, 1989.

${ }^{21}$ Cf. Id., Raisons pratiques, Paris, Seuil, 1992. 
regularidades propias, así como con las inversiones y alianzas específicas que allí se engendran, que en el caso particular de Pierre Bourdieu, respecto al mundo intelectual francés, el sociólogo se ha visto obligado a desprenderse por y contra la distancia constitutiva de la representación teórica de descubrirse en ella "comprometido", localizándose objetivamente en un espacio específico, con sus intereses e inversiones determinadas y determinantes.

Así, cualesquiera que sean sus pretensiones científicas, la objetivación está llamada a ser parcial, en la medida en que ignore o rechace ver el punto de vista a partir del cual ella se enuncia; en otras palabras, el juego en su conjunto. Construir el juego como tal, como un espacio de posiciones objetivas que marca el principio, entre otras cosas, de la visión que los ocupantes de cada posición pueden tener de las otras posiciones y de sus ocupantes, es darse el medio de objetivar científicamente el conjunto de las objetivaciones, más o menos simplistas, a las cuales se libran los agentes sociales comprometidos en la lucha, y percibir tales objetivaciones por lo que éstas son: estrategias simbólicas que tienden a imponer la verdad parcial de un grupo como la verdad de las relaciones objetivas entre los grupos. Es descubrir, además, que dejando olvidado el juego mismo que constituye a los agentes sociales en "competidores", los "adversarios cómplices" se ponen de acuerdo para enmascarar lo esencial, los intereses asociados al hecho de participar en el juego y los beneficios objetivos que de allí resultan ${ }^{22}$.

Se comprende entonces que la existencia de la sociología, como disciplina científica, se ha visto amenazada desde su fundación. La vulnerabilidad estructural que resulta de la posibilidad de "hacerle trampa" a los imperativos científicos en el juego de la politización, hace que el análisis social deba temerle tanto a los poderes que de él esperan demasiado como a los que quieren su desaparición. Las demandas sociales provienen, casi siempre, de presiones o seducciones, y el mayor servicio que puede hacérsele a la sociología del poder es tal vez no pedirle nada. Si a los "grandes maestros" se les reconoce por las páginas que nunca escribieron, ¿qué decir de los sociólogos, que son tan frecuentemente tentados a superar los límites de su ciencia? Porque no es cosa fácil renunciar a las gratificaciones inmediatas del "profetismo cotidiano", sobre todo cuando el silencio, llamado por definición a pasar desapercibido, deja campo abierto a la hilaridad estridente de la pseudo ciencia ${ }^{23}$.

La ciencia social no puede entonces constituirse sino rechazando las peticiones de los instrumentos de legitimación o de manipulación y el sociólogo —-muy a pesar de algunono tiene otro mandato o misión que el asignado en virtud de la lógica de sus investigaciones. Quienes por usurpación esencial se sienten con el derecho o se atribuyen el deber de "hablar en nombre del pueblo", aun para denunciar el racismo, la miseria o el populismo de quienes hablan del pueblo, éstos hablan por ellos mismos, o, quizás, hablan más de ellos mismos, tratando, en el mejor de los casos, de adormecer el sufrimiento ligado a la "fragmentación social", haciéndose pueblo en imaginación. Sin embargo, cuando el analista de lo social enseña a relacionar los actos o los discursos más "puros" (aquellos del científico, el artista o el militante), con las condiciones sociales de su producción y con los intereses específicos de sus productores, lejos de motivar la toma de partido por la demolición o la reducción de la cual se nutre la amargura, el investigador

\footnotetext{
${ }^{22}$ Id., Homo Acadernicus, op. cit.

${ }^{23}$ Id., Shoses dites, Paris, Ed. de Minuit, 1987.
} 
trata de liberar solamente el medio de depurar de su asepsia objetiva y subjetiva el rigorismo, más aún, el terrorismo del resentimiento, comenzando por aquel que nace de la transmutación de un deseo de "revancha social", en reivindicación de un "igualitarismo compensatorio".

Por intermedio del sociólogo, agente histórico históricamente situado, sujeto social socialmente determinado, la sociedad en la cual la historia sobrevive se vuelve un momento sobre sí misma, reflexiona y a través de ese individuo los demás agentes sociales pueden saber mejor lo que ellos son, lo que ellos hacen. Pero esa tarea es precisamente la última que confiarían al analista del poder quienes se encuentran comprometidos con el desconocimiento, la negación, el rechazo del saber y que están dispuestos a reconocer como "científicas" o de "buena fe" todas las formas discursivas que no hablan del mundo social o que hablan de manera tal que en realidad de él no hablan ${ }^{24}$.

Esa realidad negativa no tiene necesidad, salvo excepcionalmente, de declararse a través de censuras expresas. En efecto, teniendo en cuenta que la ciencia rigurosa supone rupturas decisorias con toda clase de evidencias, basta con dejar actuar a las "rutinas del pensamiento común" o a las inclinaciones del "buen sentido burgués" para obtener las consideraciones innegables del ensayismo planetario o de los "medianos conocimientos" de la ciencia oficial. Buena parte de lo que el sociólogo trabaja por descubrir, no está "escondido" en el sentido de lo que las ciencias naturales tratan de esclarecer. Muchas de las realidades o relaciones sociales no son invisibles, sino que enceguecen según el paradigma de la "carta robada", tan apreciada por Lacan; por ejemplo, la relación estadística que correlaciona las prácticas o las "preferencias culturales" con la educación recibida, debe enfrentar toda clase de "mecanismos de defensa" colectivos que aseguran una verdadera negación, en sentido freudiano.

Es así como se pueden comprender las indignaciones y reacciones de violencia extrema que suscitan, en los poseedores del capital cultural, los análisis que muestran las condiciones de producción y reproducción negadas de la cultura: a personas formadas para pensarse bajo las especies de lo único y de lo exclusivo, no se les constata sino lo común y lo adquirido. En tal caso, el conocimiento de sí, resulta ser un "descenso a los infiernos", similar a las almas que, según el mito de Er, deben beber del agua del Leteo antes de volver a la tierra para vivir las vidas escogidas, los hombres de cultura deben sus más puros "gozos espirituales" a la amnesia de sus orígenes que les permite vivir su cultura como un "don de natura".

En esa lógica, que conoce bien el psicoanálisis, esos agentes no retrocederán ante la contradicción, a fin de defender el error vital que es su razón de ser, para salvar así la integridad de una identidad fundada sobre la conciliación de los contrarios: acusarán entonces a la ciencia de objetivista, reprochando sus "absurdas evidencias", su "banalidad", su "vulgaridad"25.

Los adversarios de la sociología tienen derecho a preguntarse si una actividad que supondría y generaría la negación de una negación colectiva debe existir; pero nada los

\footnotetext{
${ }^{24}$ En ese sentido, Bourdieu señala en uno de sus últimos trabajos, cómo el "campo periodístico", y más específicamente la televisión, ejercen censuras, no sólo sobre los lecto-espectadores, sino sobre los mismos "productores de información" que "sólo hablan del mundo para esconderlo o, mejor, para mostrar una realidad completamente distinta de la realidad". Cf. Sur la televisión, Paris, Liber, 1996.
}

${ }^{25}$ Cf. Id., La distinction, Paris, Ed. de Minuit, 1979. 
autoriza a contestar su carácter científico. El análisis de las relaciones sociales devela la self-deception, la mentira hacia sí mismo, entretejida y motivada colectivamente, que, en toda sociedad, conserva el fundamento de los valores más sagrados y, por ello mismo, de toda la existencia social. Bourdieu enseña, con Marcel Mauss, que "la sociedad se paga ella misma con la falsa monedad de su sueño"; es decir, esta práctica iconoclasta de las sociedades modernas puede contribuir a hacernos un poco más maestros de la "naturaleza social", haciendo progresar el conocimiento y la conciencia de los mecanismos de todo fetichismo: las religiones seculares de los estados nacionales, el culto al arte, la ciencia y la tecnología, y los sacrificios a los nuevos "ídolos" de los medios masivos de comunicación, que contribuyen inconscientemente a la legitimación arbitraria del orden establecido.

En todo caso, puede esperarse, al menos de esta práctica social, que haga retroceder a la magia producto de la ignorancia ignorante de ella misma que, expulsada de la relación con el mundo natural, sobrevive en las relaciones con el mundo social. La revancha de lo real es implacable con la buena voluntad mal iluminada o con el voluntarismo utopista, y el destino trágico de las empresas políticas, producto de una ciencia social presuntuosa, subraya cómo la ambición mágica de transformar el mundo social sin conocer sus resortes, se expone a reemplazar por una violencia, a veces más inhumana, la "violencia inerte" de los mecanismos que la ignorancia pretenciosa quería destruir ${ }^{26}$.

\section{IV}

La sociología es una práctica científica que tiene como particularidad la dificultad de "ser una disciplina como las demás". Esto porque, según el profesor Bourdieu, el rechazo de saber y la ilusión del "saber infuso", cohabitan perfectamente, tanto en los investigadores como en los profesionales. Y sólo una disposición rigurosamente crítica puede disolver las certezas prácticas que se insinúan en el discurso científico por medio de los presupuestos inscritos en el lenguaje, inherentes a la rutina del discurso cotidiano sobre los problemas sociales, concretamente a través del ruido de las palabras que se interponen continuamente entre el analista y el mundo social. En términos generales, el lenguaje expresa más fácilmente las cosas que las relaciones, los estados que los procesos: decir, por ejemplo, que alguien tiene poder, es pensar el poder como una "substancia", una cosa que algunos tienen, conservan o transmiten; es obligar a la ciencia a determinar "quién gobierna" o "quién decide"; es, admitiendo que el poder esté situado en alguna parte, afirmar como si viniera de arriba, tal cual lo quiere el sentido común o, por una reconversión paradójica de la doxa, creer que viene de abajo, de los dominados.

Lejos de oponerse, la ilusión mecanicista y la ilusión personalista se complementan, y no acabaríamos de enunciar los falsos problemas engendrados en las oposiciones individuo frente a persona, interioridad frente a exterioridad; los debates ético-políticos entre quienes acuerdan un valor absoluto al individuo, a lo individual, al individualismo, y quienes confieren el primado a la sociedad, a lo social, al socialismo - debates de "segunda mano" del debate teórico, sin cesar renaciente entre, un nominalismo que reduce las realidades sociales, grupos o instituciones, a artefactos teóricos sin realidad objetiva, y un realismo substancialista que reifica abstracciones. Bajo pena de abandonar al "misterio" el universo de las prácticas culturales, es necesario buscar en una "historia estructural de los espacios sociales", los campos donde se engendran y efectúan las

\footnotetext{
${ }^{26} I d$., "La production de la croyance: contribution á une économie des biens symboliques", en ARSS, 13, Paris, EHESS, 1977.
} 
disposiciones que convierten a los hombres en políticos, en artistas, en intelectuales o en científicos $^{27}$.

El principio de la "acción histórica", la del artista, la del científico o del gobernante, como la del obrero o del pequeño funcionario, no es un sujeto que se enfrenta a la sociedad como a un objeto constituido en la exterioridad. Ese principio no reside ni en las conciencias ni en las cosas, sino en la relación entre los estados de lo social: entre la historia objetivada en las cosas, bajo la forma de instituciones y entre la historia encarnada en los cuerpos, bajo la forma de disposiciones durables. El cuerpo está en el mundo social y el mundo social está en el cuerpo. Y la incorporación de lo social que realiza todo aprendizaje es el fundamento de la "presencia en el mundo" que supone la acción socialmente reconocida y la experiencia ordinaria de ese mundo como "evidente".

Pensar cada uno de esos universos particulares de la producción cultural, tal como lo ha hecho Pierre Bourdieu, en términos de campos, es permitirse el medio de entrar en el detalle más singular de la realidad histórica, a la manera de los investigadores minuciosos que perciben "configuraciones estructurales de relaciones" o, simplemente, "casos particulares de lo posible". Esto supone una mirada atenta a las "relaciones pertinentes", generalmente desapercibidas a primera vista, entre las realidades realmente visibles, como las personas individuales, designadas por nombres propios, o las personas colectivas, a la vez nombradas y producidas por el signo o el siglo que las constituye en "personalidades jurídicas". De suerte que, así como Poincaré definía las matemáticas como el "arte de dar el mismo nombre a cosas diferentes", Pierre Bourdieu diría de su sociología - con la venia de los matemáticos, que es "el arte de pensar cosas distintas como similares en su estructura y funcionamiento".

Así, transfiriendo lo que ha sido establecido a propósito de un objeto construido, por ejemplo del campo religioso, es posible pensar toda una serie de nuevos objetos: el campo artístico, el campo político o el campo científico. Gracias al uso del método comparativo, al cual el pensamiento sociopolítico confiere su plena eficacia, la ciencia social puede aprehender un número cada vez más extendido de objetos con un número cada vez más reducido de conceptos e hipótesis teóricas.

Realizar análisis sociales, en términos de campo, exige una conversión de toda la visión ordinaria del mundo que se apega a las cosas visibles: al individuo, al cual nos liga una suerte de "interés ideológico primordial"; al grupo que no está aparentemente definido por las solas relaciones temporales o durables, informales o institucionalizadas entre sus miembros, y a las relaciones entendidas como "interacciones" (relaciones intersubjetivas realmente efectuadas). La noción de campo supone una ruptura con la representación realista que trata de reducir el efecto del medio al efecto de la acción directa por medio de una "interacción". Es la estructura de las relaciones constitutivas del campo lo que ordena la forma como pueden revestir las relaciones visibles de interacción, así como el contenido de la experiencia que los agentes sociales puedan tener de ella ${ }^{28}$.

La atención al espacio de relaciones, en el cual se mueven los agentes sociales, implica una ruptura radical con la "filosofía de la historia", inscrita en el uso ordinario o en los hábitos de pensamiento asociados a las polémicas de la política, en donde suele ser necesario, a toda costa, encontrar responsables de lo mejor como de lo peor. Serían

\footnotetext{
${ }^{27}{ }^{9}$ Serfa hacer el "desmontaje impío de la ficción” como lo realizó Mallarmé en el "campo literario". Cf. Pierre Bourdieu, Les régles de l'art. Genése et structure du champ littéraire, Paris, Seuil, 1992.

${ }^{28}$ Id., Réponses, op. cit.
} 
inagotables los errores y las mistificaciones que se engendran si se miran los sentidos que las palabras adoptan cuando designan instituciones o grupos: Estado, Burguesía, Patronato, Iglesia, Familia, Escuela, Trabajo..., pueden ser constituidos en sujetos de la forma "el Estado decide" o "la Escuela elimina", y entonces transformarse en realidades que pretenderían estar "más allá de la historia", capaces de realizar sus propios fines. Así, procesos de los cuales el sentido y el fin no pensados ni determinados por agentes concretos, sin ser ciegos ni torios, pueden encontrarse ordenados en referencia a una intención que no es la de un "creador" concebido como persona, sino a la voluntad de un grupo o de una institución funcionando como "causa final", capaz de justificarlo todo y, al mínimo costo, sin explicar nada.

Ahora bien, es posible mostrar, como lo hizo Pierre Bourdieu apoyándose análisis de Norbert Elias, que esa visión teológico-política no es consistente siquiera en el caso aparentemente mejor fundado para justificarla, el de un estado monárquico que presenta al más alto grado, gracias al rey mismo - “l'Etat c'est moi"- las apariencias del sistema totalitario: la sociedad cortesana funciona como un "campo de gravitación" en el cual el detentor del poder absoluto esta allí también incluido, a pesar de que su posición privilegiada le permite preservar la mayor parte de la energía social engendrada por el "equilibrio de fuerzas". El principio del movimiento perpetuo, que agita al campo del poder, no reside en un primer motor inmóvil, sino en las tensiones que, producidas por la historia constitutiva del campo (diferencias de rango y jerarquías), tienden a reproducir en su totalidad esa estructura. Dicho de otra manera, el movimiento del campo radica en las acciones y reacciones de los agentes que, a menos que estén excluidos del juego, no tienen otra escogencia que mantener o mejorar su posición en el campo, contribuyendo así a hacer pesar sobre los demás las obligaciones, frecuentemente vividas como insoportables, que nacen de la existencia antagonista — del hecho mismo de la posición que ocupa en el campo de gravitación del cual él es el sol, el rey no tiene necesidad de querer siquiera pensar su sistema solar en cuanto tal para mantener las ventajas de un espacio que gira a su beneficio. Tanto en el campo religioso, como en el campo del poder, los dominantes son quienes expresan las fuerzas inmanentes del campo, mucho más que los que las producen o dirigen ${ }^{29}$.

Gracias a que los agentes sociales estamos siempre más o menos comprometidos en uno u otro juego de la producción cultural, no se nos ocurre preguntar por qué hay acción antes que nada, lo cual - a menos de suponer una propensión a la acción o al trabajo- no es absolutamente evidente. Cada quien sabe, por experiencia, que lo que hace correr al alto funcionario puede dejar al investigador indiferente, y que las inversiones del artista suelen ser muy poco inteligibles para el banquero. Así pues, un campo no puede funcionar si no encuentra individuos socialmente predispuestos a comportarse como agentes responsables, capaces de arriesgar su dinero, su tiempo y, a veces, su honor o sus vidas con el único fin de apostarle a uno de los juegos sociales que troquelan su ser, y obtener los beneficios deseados; ventajas que, vistas desde otro ángulo, pueden parecer ilusorias o banales, cosa que no deja de ser posible, pues reposan en la relación de "complicidad ontológica" entre lo que Pierre Bourdieu llama habitus y campo, que es el principio de toda entrada en cualesquiera de los juegos posibles, de la adhesión a algún juego, de una ilusio ${ }^{30}$.

Es en la relación entre el juego y el sentido del juego donde se engendran los intereses y se constituyen valores que, aunque no existen por fuera de esa relación, se imponen en

\footnotetext{
${ }^{29}$ Id., Raisons pratiques, op. cit.

${ }^{30}$ Ibid., ver especialmente el capítulo que podría traducirse como “¿Es posible un acto desinteresado?”. 
el interior de ésta, con una necesidad y una evidencia absolutas. Esa forma original de todo fetichismo es el principio de toda acción. El motor -aquello que a veces se llama motivación - no reside ni en el fin material o simbólico de la acción, como lo desea el finalismo ingenuo, ni en las obligaciones del campo, como lo quiere la visión mecanicista. La motivación reside en la relación entre un habitus y un campo, que hace que la disposición contribuya a determinar lo que lo determina. En efecto, no hay nada sagrado sino para el sentido de lo sagrado, que reconoce lo sagrado como "plena trascendencia". Lo mismo podría decirse de toda especie de valor: la ilusio en el sentido de inversión en el juego, no se vuelve ilusión, en el sentido original de engañarse a sí mismo, de divertimento — según Pascal—o de mala fe —según Sartre—, que cuando se aprende el juego desde afuera, como un espectador imparcial que no invierte nada, ni en el juego ni en las "apuestas" del juego.

Ese punto de vista de extranjero tiende a ignorar que las apuestas son "ilusiones bien fundadas" y que por medio de los juegos que el mundo social propone, la sociedad procura a sus jugadores mucho más que los intereses aparentes del juego, los fines manifiestos de la acción: "la caza cuenta tanto o más que la presa", y hay un beneficio de la acción que excede los beneficios explícitos perseguidos (salarios, premios, recompensas, medallas, diplomas, trofeos, títulos, funciones) y que consiste en el hecho de "salir de la indiferencia", de afirmarse como agente actuante, jugador que juega, sujeto ocupado, habitante del mundo habitado por el mundo, proyectado a ciertos fines y dotado, objetiva y subjetivamente, de una "misión social"31.

\section{V}

Las funciones sociales son "ficciones bien fundadas", y los ritos sociales de institución hacen a quienes consagran en tanto rey, caballero, sacerdote o profesor, forjando su imagen social, construyendo la representación que el iniciado debe dar en tanto "persona moral"; en tanto plenipotenciario o portavoz de un grupo. Empero, esas ficciones fundan en otro sentido: imponen un nombre, un título que define, instituyen y constituyen, obligan a hacer lo que hay que hacer, lo que se debe ser conforme a una función, a la entrada a un juego, a la ficción, a jugar el juego, la función. Y entregándose en cuerpo y alma a su función, y por intermedio de ella, al cuerpo constituido que la confía universitas, collegium, societas, consortium, como decían los canonistas, el heredero legítimo, el funcionario, el dignatario, contribuye a asegurar la eternidad de la función que lo pre existe y lo sobrevive -dignitas non moritur- místico que él encarna y del cual él participa, compartiendo ésa eternidad.

Aunque el análisis del poder debe rechazar, para constituirse, todas las formas de biologismo tendientes a "naturalizar" las diferencias sociales, reduciéndolas a "invariantes antropológicos", el pensamiento sociopolítico no puede comprender el juego social en su aspecto más esencial, sino a condición de tener en cuenta ciertas características de la existencia corporal, como el hecho de existir en tanto individuo (masculino o femenino), o de haber nacido y habitar un lugar y un momento determinados, o el hecho de estar y saberse destinado a morir — propiedades que lamentablemente a veces se excluyen de la axiomática

positivista

\footnotetext{
${ }^{31}$ Id., Méditations pascaliennes, Paris, Seuil, 1997.
} 
32. Ordenado a la muerte, ese fin, que no puede ser tomado por fin, el hombre aparece como un ser "sin razón de ser". Y es la sociedad, y sólo ella, quien dispensa a diferentes niveles, las "justificaciones de existir"; es ella quien, produciendo los negocios o las posiciones llamadas "privilegiadas", produce actos y agentes que juzga "importantes" para ellos mismos y para los demás, personajes objetiva y subjetivamente asegurados de su valor y, por consiguiente, arrancados de la indiferencia y la insignificancia.

Hay una filosofía de la miseria que está más cerca de la desolación de los ancianos indigentes de Beckett, que del optimismo voluntarista tradicionalmente asociado al pensamiento progresista. "Miseria del hombre sin Dios", decía Pascal; "miseria del hombre sin misión ni consagración social", diría el socioanálisis. En efecto, sin atreverse a afirmar, Pierre Bourdieu, como Durkheim, que "la sociedad es Dios", en variadas ocasiones el célebre profesor del Colegio de Francia dijo: "Dios no es más que la sociedad". Lo que se espera de Dios, sólo se obtiene de la sociedad, la cual únicamente, tiene el poder de consagrar, de liberar de la contingencia, de la indiferencia, del absurdo; pero solamente de manera diferencial y distintiva: todo lo sagrado tiene su complemento profano, toda distinción produce su vulgaridad, y la competencia por la existencia social reconocida, que aparta de la insignificancia, "es una lucha mortal por la vida y la muerte simbólicas"33.

La visión lúcida de la verdad de todas las misiones y de todas las consagraciones, no condena ni a la dimisión ni a la deserción. Se puede siempre entrar en un juego sin ilusiones, pero con una resolución consciente y deliberada. Sí quienes tienen pactos con el orden establecido no pueden gustar del análisis del poder, es que esta práctica introduce una libertad con respecto a la adhesión primaria que hace que el conformismo adopte un aire de herejía e ironía.

Tal ha sido, pues, mi recuento de "la lección sobre la lección" en torno a la sociología política de Pierre Bourdieu que, en tanto discurso reflexivo, presenta un carácter insólito e insolente. $Y$ es porque una teoría de los "campos del poder" y las "márgenes de la libertad", que se objetiva a sí misma, rompe forzosamente el encanto, desencanta. Porque este tipo de pensamiento atrae la mirada sobre lo que se olvida y se contribuye consciente o inconscientemente a olvidar. Porque, además, es una propuesta, que al ser compartida por quienes la enuncian, introduce una distancia que amenaza con anonadar, tanto en el orador como en el público, la creencia que es la condición ordinaria del funcionamiento satisfecho de la institución. ¡Cuánto provecho y malestar causaría en Colombia la aplicación de un pensamiento como éste!

\footnotetext{
${ }^{32}$ Ser hombre o mujer, casado o soltero, joven o viejo, son categorías sociales de clasificación que tienden como tales a reproducir los mecanismos estructurales de la dominación, especialmente aquella que está más enraizada en el inconsciente. Cf. Pierre Bourdieu, La Domination masculine, Paris, Seuil, 1998.
}

${ }^{33}$ Id., Méditations pascaliennes, op. cit. 